\title{
CHAT WITH BRANKO KOLAREVIC
}

\section{BATE-PAPO COM BRANKO KOLAREVIC}

\author{
Gabriela Celani (editor)
}

Associate Professor, School of Civil Engineering, Architecture and Urban Design, University of Campinas, celani @ fec.unicamp.br.

\begin{abstract}
On December 18, 2013, a group of researchers from LAPAC, the Laboratory of Automation and Prototyping for Architecture and Construction, at the University of Campinas, had a video-conference with Prof. Branko Kolarevic, from Calgary University. Although the main objective of the talk was to discuss the question of digital fabrication and its impacts in the making of buildings, each researcher had the opportunity to ask something about their own topic of research, which are all related to computational design: parametric modeling, the use of programming in the creative process, responsive architecture and evolutionary computation. Among these researchers were students with different backgrounds - architecture, civil engineering, mechatronics and computer science - and at different levels, from undergrads to $\mathrm{PhD}$ candidates.
\end{abstract}

Key-words: digital fabrication; architectural detail, computational design.

\section{Resumo}

Em 18 de dezembro de 2013, um grupo de pesquisadores do LAPAC, o Laboratório de Automação e Prototipagem para Arquitetura e Construção, da Universidade Estadual de Campinas, realizou uma videoconferência com o Prof. Branko Kolarevic, da Universidade de Calgary. Embora o objetivo principal da conversa tenha sido discutir a questão da fabricação digital e seus impactos na produção de edifícios, cada pesquisador teve a oportunidade de discutir seu próprio tema de pesquisa, todos relacionados ao computational design: modelagem paramétrica, uso da programação no processo criativo, arquitetura "responsiva" e computação evolutiva. Entre esses pesquisadores havia alunos com diferentes backgrounds - arquitetura, engenharia civil, mecatrônica e informática - e em diferentes níveis, desde graduandos até doutorandos.

Palavras-chave: fabricação digital; detalhe arquitetônico, computational design.

Gabriela Celani: Hi Branko and thank you very much for joining us for this informal chat.

Branko Kolarevic: Hi! It is a pleasure to meet you all.

G.C.: Jarryer will start with a question related to his research.

Jarryer de Martino: The use of evolutionary algorithms helps us to search for the best solutions and sometimes it is possible to find those that we never imagined. So, EA could be applied to exploration and exploitation, turning it into a performative design process. Do you believe the use of methods based on EA could increase the level of detail in an architectural design project?

B.K.: The use of evolutionary techniques can add a considerable level of details to a design. I don't know if you mean tectonic details, I'm not aware of anybody using that, but there are uses of evolutionary techniques for detail design. Some early work by Cristiano Ceccato ${ }^{1}$ at the Architectural Association (AA), at some point he was commissioned to design door handles. It was one of his early projects when he picked a door handle that was designed by Alvar Aalto and another design by [another architect]. He created a genetic algorithm to combine these two designs and then he created a new style of door handles. That is an example of the use of evolutionary design in architectural details. (...) you can extend that for all sorts of tectonic detailing. For example, you can take the connector of two pipes, a complex shape, and combine two types of connector and get all different types of shapes using a genetic algorithm.

Wilson Barbosa: Regarding the digital fabrication of building parts and details, what can be the consequences for the final product if the designer is not aware of the "file to factory process", that is, if s/he doesn't know how the CNC machine works, and has never experienced the development of a product with the use of such machines?

B.K.: It's hard to deal with ignorance. People somehow need to become aware of technologies and there are different ways by which that can be done. Of course on the professional literature the technology has been described. And I believe it's the case around the world. And a second [way] is to encounter this technology by working on a project. It's very common in the industry. Most of the folks that work with sheet metal, they do have CNC technology. It is likely that the architect who is interested will learn about the technology by visiting the shop.

Daniel Lenz: Jon Gertner, in The Idea Factory, attributes to Mervin Kelly, director of Bell Labs in 50's, the definition that innovation is some technology that has a big impact on society doing a job better or cheaper, or both. If digital fabrication is 
so powerful when it comes to flexibility of shapes and precision, why do you think a technology that has been around in Brazil since the second half of the 80's is still unusual in architecture? Do you think it is mainly a cultural, time, or economic issue?

B.K.: Well... few architects get close to how things are made, so I'm not surprised that people are not aware of these technologies in some parts of the world. But the people who are engaged in fabrication especially in metal fabrication are likely to have CNC technologies in their shops. It's been around for quite a long time... The reason [not to use it] is cultural and to some extent costs. (...) You want to make your mark in any contemporary architecture.

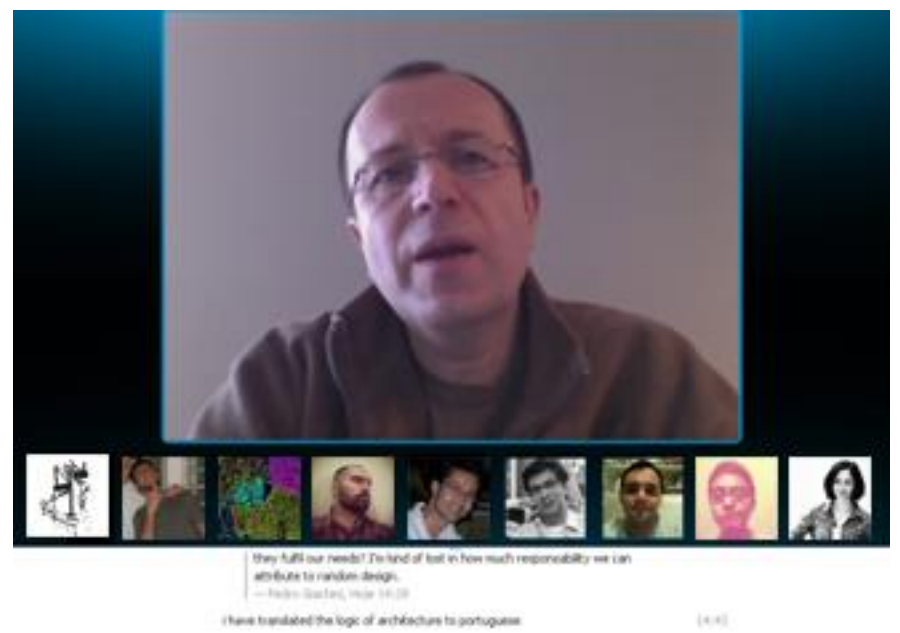

Figure 1: Print screen of the video-conference window.

D. L.: One may have automation in either two ways: a passive one, temperature reaches certain level and the thermostat goes off, turning off a heater, for instance; or a computed one, a computer reads the level of a sensor (a thermostat), and take some action related to it, let's say, turn off a heater. Both may have the same behavior, and let me call it performance. But this computational automation has an infinitely larger flexibility even with a restricted hardware. I'd like you to comment on this flexibility, and how may it affect architectural systems, as the same system/hardware can present performances related either to efficiency or to art/communication.

B.K.: I'll be addressing this question in my new book Building Dynamics: Exploring Architecture of Change, where I'm actually looking at adaptive, performative and interactive systems in architecture. What would be the addition of the computer to these building systems that could add attraction? In the case of a thermostat the operation is really simple. It contracts or expands depending on the temperature of the room and it can trigger a certain action, but when you have a computer you can have much more complex set ups, with some [information] from the users who are in the room. We can imagine a family in which the father and the mother and the children can create some algorithm that establishes some priorities such as what time of the day they would be able to control the temperature, or maybe the thermostat controls the temperature randomly (...) But this could become boring very quickly. The challenge related to interaction is how to keep technology mutually engaged. Some people have written about this in the past [such as] Gordon Pask, who taught in the late 60 's. In a short article about design he described the conversation theory. One needs to have a conversation with the technology so to speak - to make it engaging.

Pedro Giachini: In your article, you mention that today we have an infinite variability in design, so we don't need more "grids" and "modules". But I wonder if we as humans still feel the need for patterns to identify space. I read somewhere that people prefer to gather near walls or pillars in large spaces (like airports). The question is: we have infinite design options, but do they fulfill our needs? I'm kind of lost in how much responsibility we can attribute to random design, how can we choose which is the good one.

B.K.: This new world where the designer establishes the parametric settings and then somebody else is doing the actual design. Who has the responsibility for sorting out the bad designs? Someone will have to take into account the functional aspects of the design, and I believe those could be coded in, in order, for example, to not make a door handle that is too thin and will break, or is too big, so the hand cannot grasp it, so those functional considerations could be embedded in the code. When things become critical is in aesthetics, and I believe your question relates to the aesthetic dimension. How to make sure that something is qualitatively good. (...) Beauty is not something that you measure on a scale, one to ten, because one for me may be ten for you or ten for Gabi. Beauty is in the eye of the beholder. So the tricky thing is: do we absolve ourselves from the aesthetic responsibility when we design a parametric system that is released to the public, or do we attempt to kind of encode our own aesthetic biases in this parametric system? We are yet to see such technologies being used in public domain (...). I was in a conference two weeks ago in Rio, where José Duarte, from Lisbon, shared with the audience what he's working on, mass customization. And one of the projects that he showed were dinner plates where he worked with a Portuguese company to create a parametric system that will be available in a website, so the customers can design their own dinner plates that will then be manufactured by the ceramic company. So Jose and I had the chance to talk a lot about it and I asked him whether he had encoded "good design" into the system, so one cannot make [for example] a tiny tiny bowl that has a huge rim all around it, making it dysfunctional and also ugly. So these are the things that I think will come into focus, for the parametrics to enter the public domain, for the development of products through online parametric systems.

P.G.: I'm a civil engineer, I never studied architecture. When does the learning of parametric tools come in the education of architects... in undergrad school, grad school? Do you think it should be part of their education, or each person should look for it? Is it for everyone?

B.K.: I can share my own experience in our architecture program in Calgary. I have been the director of the program for three years. We made the decision to introduce parametric design in the first year of our master program in architecture. It's in the design techniques course. Students first learn freehand sketching, painting, then we move them into Adobe's suite - Illustrator, Photoshop, and then they start doing some 
3D modeling, and in the second semester they start working with Rhino and start using Grasshopper, and very quickly they pick up Grasshopper and the parametric richness that Grasshopper can bring to that. So we introduce that to students very early on. It is a curricular choice that we made collectively in our program. That was no my decision, it's a collective decision that the group has made several years ago. It is really a question of pedagogic philosophy that each school should develop. (...) In our view this is an important concept to be brought on very early. And I also want to relate that to an experience that I had as a student more than 20 years ago. I went to the Harvard School of Design in Harvard University. I was there in the late 80's, and Bill Mitchell - who unfortunately passed away - was then teaching a course called Fundamentals of Computer-Aided Design ${ }^{2}$. It was a required course for all 1st year students in all the disciplines architecture, landscape architecture and urban design. And in that course we were introduced to programming in Pascal. It was not similar to Grasshopper but there was a tool that had been developed by some doctorate student which helped everybody to develop their programs. It was a pedagogic choice that was made early on and was probably way ahead of its time. Probably about three quarters of the students were scratching their heads trying to understand why on earth they were being tortured with programming in Pascal. Very few of them saw the relevance of what they were doing. Bill Mitchell was somebody who was thinking way ahead of everybody else. Fifteen years later parametrics pretty much became the norm in the architectural world of the so-called developed countries. In a sense Grasshopper is a wonderful tool that is making parametrics accessible to a really large number of people that are beginning to see the advantages of it. I literally expect to see an explosion of the parametric design and I expect those things to [be used] in the public domain.

Fabio Azevedo: Was it worth the torture learning Pascal back in those years?

B.K.: [It was not torturing] for me because I had programming in my High School and I was keenly interested. I went to Harvard to specialize in the subject. The difficulty of programming for architects is that it requires a kind of rigorous logical thinking. You need to provide a clear structure to something that is by definition highly unstructured. When I say "something" I'm referring to conceptual design. Because for most designers the early phases of design are anything but rigorous. They are kind of loose, non-linear, loopy, explorations of all sorts of different ideas. There was an inherent contradiction in trying to bring a tool that relies in a structured logic into something that defies the introduction of logic. It was only when the design begins to take shape; one form or another; that this technology begins to demonstrate its strategy. Because you then begin to describe the design space of alternatives that could be then quickly explored. Bill Mitchell has written a book called The Logic of Architecture ${ }^{3}$. Which I think is one of his best works and it's not really wellknown to the broader public and I think he considered this book his most seminal work, where he was actually trying to elucidate this question called logic structure in architectural design. And it shows that long lineage of that logically structured thought. (...) I don't think there is a clear-cut answer. I think there is a contradiction in trying to bring some logic to something that is highly unstructured. I think this is going to strive with us for a while. And the beauty of Grasshopper is that it permits a fluid restructuring reorganization of the dependences of the geometry. People who are visually inclined, who are not necessarily interested in the hard coding, in writing code "by hand". And the success of Grasshopper applies precisely in its ability to facilitate easy visual manipulation of the underlying organization of the geometry.

F. A.: It's becoming better than what I expected! You just mentioned one of the key questions that I have been addressing in my research with Gabriela which is this gap between what architects are more used to using - visual things, to which they are daily exposed and required to learn - and then they are introduced to programming. So I thought why not do some exercises with this visual aspect first for introducing the hard concepts. Maybe you were exposed, in some programming course or some data structuring course that are common in computer science, to algorithmic animation. It is common in computer science to use animation to explain hard concepts for those who are still not well acquainted with logical thinking. That is what I'm trying to explore. I'm trying to propose the use of algorithmic animation for introductory courses of programming for architects, (...) to construct a step by step understanding. Do you think it's a reasonable idea or something to explore?

B.K.: It's certainly worth trying, and the tricky thing for you if you want to be rigorous in that experiment - is to develop a metrics by which you could judge whether you are being successful or not. You would need to have some baseline to compare with the results. I would imagine introducing a group to structured thinking by using Grasshopper, using algorithmic animation, using scripting such as Rhino scripting or some other scripting language and so on, and then developing some tools that would enable you to compare the outcomes. I think that could be a necessary step to judge how successful each of these methods would be to a classroom or a studio.

Maycon Sedrez: Brazilian architects don't have full access to digital fabrication equipment. Also, we still have a modernist aura slowing down the adoption of complex forms in architecture. Do you think the manufacturing of material effects will ever be an alternative for our architecture? What is your opinion about the new ornament resulting from digital techniques? How can it go further than an aesthetic exploration?

B.K.: Architects might be ignorant of digital fabrication, and I don't really blame them. But I think you would be surprised with how much of this technology is actually accessible almost universally. I've discovered that in various parts of the US and Europe the folks who are involved in metal sheet fabrication aluminum, steel, any kind of metal - they do have CNC capabilities. I bet that if you were to go around Campinas you would find a lot of metal shops and all of them can have some CNC capacity. (...) Going back to the question of ornament, I've written about this in Manufacturing Material Effects. (...) Ornament has been banished from architecture pretty much in the second half of the 20th century. Maybe starting in the 
1930's or so, with what we call modern architecture. If you look at earlier periods, even if you go back to antiquity, you will find an innate, inherent desire to add definition to the surfaces in the environments that are occupied by humans. And the reason for that has to do with pleasure. It's really interesting to look at the work of Adolf Loos, who became famous for claiming that ornament is crime. But actually what he meant was that the Victorian ornament was crime. Like the one where you had this extreme plasticity in the interiors. (...) In his interiors he used wood inlets. The geometry was plain, flat, but then each of the surfaces had a rich articulation. For example in Michaelerplatz, the building across from the Imperial Palace, he uses this richly textured stone to add what I will call ornament. In this case ornament was inherent to the material. The material itself was ornamented. One can choose what the material has to offer. Look at the Barcelona Pavilion by Mies van der Rohe. He is using four different kinds of stone, and some of the stones are incredibly colorful and richly textured. So one can work with the material or one can work with plain materials that lack this kind of texture, this kind of intricate composition, and then provide that intricacy through the definition of the geometry. So, one can create interesting carving patterns, like Herzog \& de Meuron did in some of their buildings, like the Walker Art Museum in Minneapolis and so on. And the reason why we want ornamentation - and again it has to do with what I have called visual richness in the environment - we have a visual cognitive system; our eyes look for stimulating contexts. And when the eye looks at an urban environment - let's think about the scale of the city - to see that you have that repetitive pattern in the building that is monotonous, that is not particularly interesting, and in those instances our cognitive apparatus just disconnects because there is nothing for it to read. In an Art Nouveau or some kind of intricate fence for example the eye would remain engaged, looking for the underlying structure. If the underlying structure was hard to detect our visual cognitive system would disconnect. It disconnects at extremes. When the structure is too apparent or when the structure is too complex. Whereas it remains engaged in that medium range, where it can see that there is an interesting structure, it can understand that there is a structure, but it cannot exactly decide for what the structure is. And I would argue that Adolf Loos, Mies van der Rohe, and many architects of the past understood the essence of that game of engaging the eye of the viewer in the spaces that they designed. And I have to say that I'm pleased with what has been happening in interior design. It understands this notion of engaging the viewer in a particular context. Certain things could become distractive, and I would imagine that there are instances where you do not want this kind of visual distraction to be present. But again we're living in an aesthetically interesting time, when we are going to see some bad uses of the new opportunities that are brought by these technologies, but we are going to see also some incredibly refined, subtle employments of parametrics and digital fabrication in that kind of intricate, ornamental, decorative articulation, not only in interiors but also in the exterior of buildings. This can be used for the good and bad, and ugly and my concern is that we are going to see a lot of bad and a lot of ugly.

G.C.: You mentioned that if we look around we could find some forms working with CNC machines in Campinas. This is exactly what Wilson did in his research. He worked with a nearby plasma cutting company. Can you talk a bit about that Wilson?
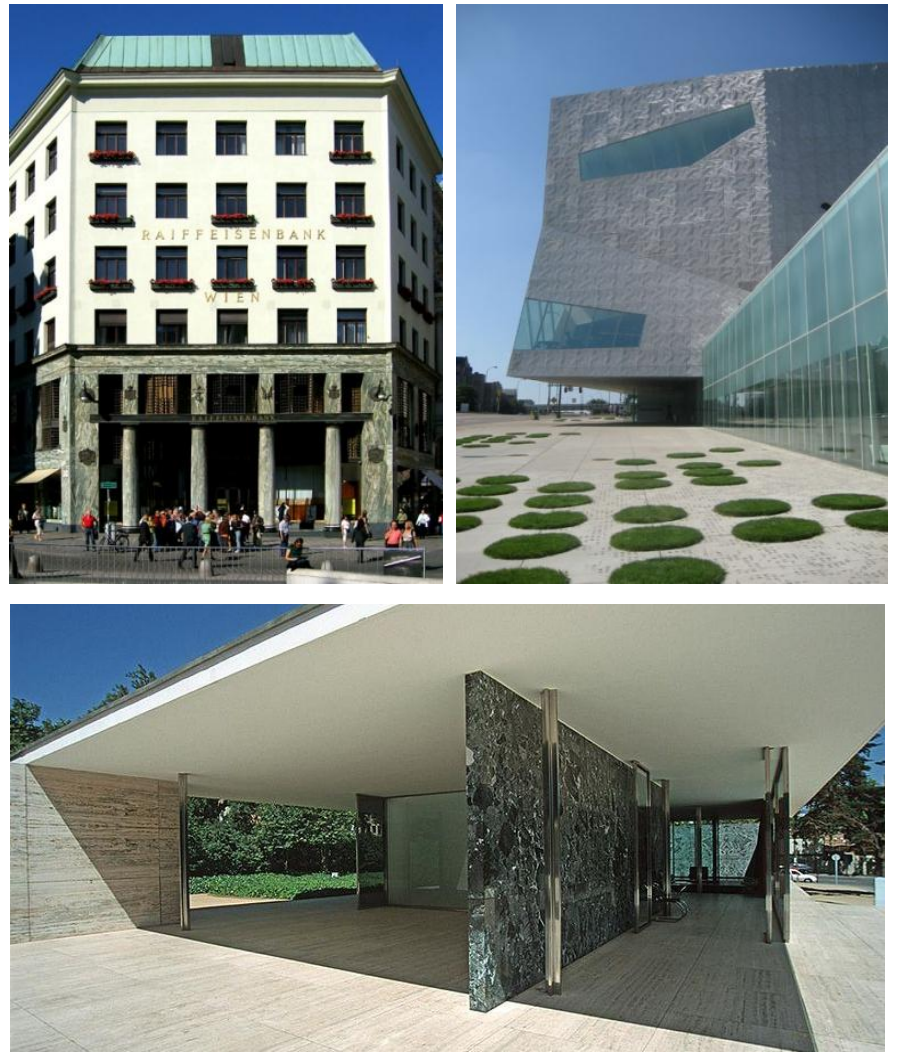

Figures 2-4: (Clockwise). Michaelerplatz; Expansion of the Walker Art Museum; Barcelona Pavilion. Source: Wikipedia.

W.B.N.: I did my research in a local steel cutting company. They do a lot of mechanical parts for the industry, but nothing for architecture, and when I came up with my idea to investigate the use of CNC companies for architecture and design applications they were very impressed, because it's a field in which they don't usually offer services (...) but they gave me the opportunity to try to use the machines. They said the problem was that architects didn't know the specific type of materials or type of drawings or the type of files that they use.

B.K.: Yes! It is a process. We discovered that technology very late. It needs to occur in the professional side. That hopefully will come to your generation. [It was not present] in our generation, how Gabi, myself and our colleagues were educated, but you folks... it's people like yourselves that will begin this change. We educate the future professionals to use these technologies in their work. And I've seen this happening in various parts of the world. What the late 1990's in the US is now present in various parts of the world. You see these technologies more and more being used - sometimes in a traditional manner, but it's becoming a normal thing. We see some more refined outcomes and again some unfortunate outcomes. In Philadelphia, where I started teaching digital morphogenesis and then digital fabrication in the late 1990's, and I had a group of students who wanted to do a thesis with me to design an [information kiosk for the university community] in Philadelphia; and they had some funding and they estimated that they would need about US\$50.000, and I 
said I don't have that much money for it, so you will have to do your own fund-raising. They found a fabricator who actually wanted to donate all the material, and he was interested in a project for the community in which he could showcase their expertise. So the students actually didn't even spend the money that I gave them. The kiosks were built and the fabricator used this to advertise its services. So if you have that shop in Campinas you could find some interesting use of this technology and have it featured in something and the fabricator can use it for advertising his services.

André Araújo: In the book Architecture in the Digital Age: Design and Manufacturing, you affirm that the transition towards the digital age puts the architect closer to craft. On other hand, one of the challenges of contemporary architecture is to integrate knowledge from other areas. In your opinion, what's the best moment to integrate other professionals in the form finding process? And what's the best way to bring it to the early stages of design?

B.K.: It's actually related to the nature of the project. When one is designing a high rise building and is interested in doing something innovative he will team up with engineers, structural engineers, mechanical engineers... let's say you are interested in natural ventilation in a 50 story building. How do you do that? You are interested in the natural conductive process, how the air moves naturally through the building, towards the top, as it is heated by the computers, the people and so on. Then you can think about some strategies to use the wind around the building to move some fans and to generate electricity. Then you have mechanical engineers working with fluid dynamics, structural engineers who can help design the structure so the building faces the dominant wind. I'll give you an example. There is a building that was designed by SOM, from Chicago, that was built in Guangzhou, in China. It's called the Pearl River Tower. It was completed in 2009. It's a 70 story building. It has natural ventilation. And it's not built in the United States, it's not built in Europe. It's built in Guangzhou, in China. So that is a good example of close collaboration between architects and engineers. There is a long article about that building that was published by Architectural Record. And the SOM office in Chicago is actually known for hiring both architects and engineers.

Pedro Veloso: As you pointed out in Towards Integrative Design, we are witnessing the diffusion of a geometrical complexity that is inspired in (or sometimes even borrowed from) other fields' processes and techniques. We can materialize these patterns with digital and robot fabrication in several materials, almost without joints or restrictions of scale. How do you see this redefinition from the point of view of tectonics and architecture detailing? Does it imply that the jointless (non) detail is the new prevailing detail for architecture?

B. K.: This kind of jointless, non-detail is probably an option now, but it's contradictory. I'll give you an example. I was invited to write an article for an issue of Architectural Design [AD], and the subject for the issue was High Definition: Zero Tolerance in Design and Production [coming out in January 2014]. The issue is edited by Bob Sheil. In that issue it was argued that the precision of digital fabrication could lead to zero tolerance in design. But I kind of questioned that, because with the great precision that we now have access to, the zero tolerance is not worth chasing, because there is a dynamic behavior of [building components]. Structure moves, parts of the facade will begin to move, because of the stresses and the forces that are being introduced in the assemblage. And there is a great deal of tectonic engineering that goes in the design to allow the parts to move seamlessly into each other. In high rises the buildings can swing easily five meters. That dynamics of the behavior needs to be somehow dealt within the tectonic articulation of the building. Even if we could fabricate with great precision there is still a great amount of [movement that needs to be dealt with]. Think about concrete forming and concrete casting. A difference of 2 to $5 \mathrm{~cm}$ is very common in that context. Our industry has a long tradition in accounting for these imperfections. There are adjustable details. So when one connects a precisely fabricated part to a concrete part there will be imprecisions that need to be accounted for through really ingenious ways of designing details. And when that ingenious detail does not exist the building leaks, like at MIT's Stata Center, because there are cracks that become bigger and bigger, and that happens because stresses that affect the building are not adequately dealt with [see http://tech.mit.edu/V127/N53/lawsuit.html]. And parts that were supposed to be perfectly joined are not joined at all. Another example that I gave was the differential behavior of materials. Certain materials behave very differently at different temperatures. (...) One needs to design the details with that behavior in mind. (...) I don't think that this kind of jointless, non-detail building will ever become a reality in architecture quite the contrary.

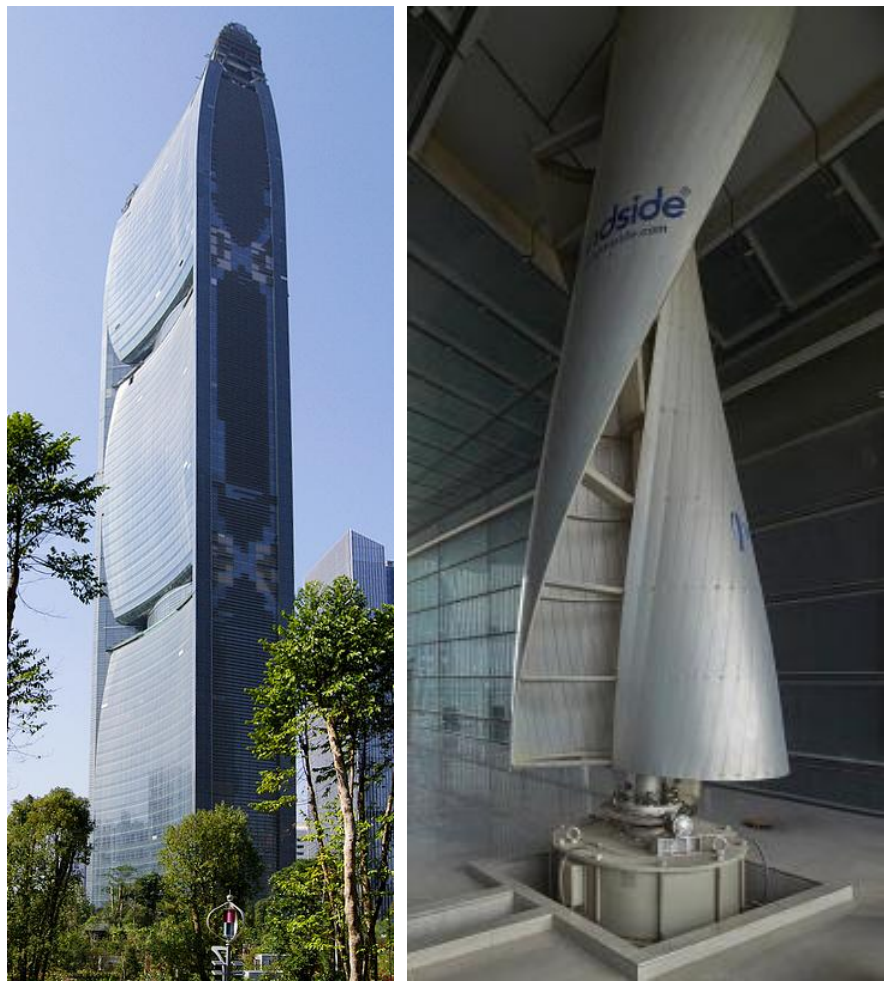

Figures 5-6: Pearl River Tower. Source: (Left) Wikipedia; (Right) www.som.com. 
Vinicius Mizobuti: Your paper was about the democratization of design. Do you think that in the future architects will become more programmers than architects? Because you said that in the future the client will be able to go online and participate in the design process. Does that make the architect less of an architect and more like a programmer?

B.K.: My hope is that technology will become transparent. We no longer will have to talk about whether programming was used or not. With my students, I come to a design review; I see some intricate facades, but it's now becoming natural to the process. We no longer ask the students how they did that; we just discuss the design and the aesthetic outcome. We will soon talk just about the things that matter, the quality of the space. The technologies are going to disappear in the background. (...) I mentioned the [parametrically designed] dinner plates that are now going to become accessible in Portugal, by a Portuguese maker of ceramics. I argue in my article [that will be published in the next issue of AD, in January 2014] that we have all the technologies that make possible that interaction, that parametric design created by someone. The issues are mainly cultural, whether the public will have the confidence to design something. I ask myself, and I give you an example. Let's say that a car manufacturer suddenly allows people to design their own cars. I ask myself - will I have the confidence to manipulate that kind of design, so I can choose the hump of the car, the hood, the size of the wheels and so on. I will probably find a friend who understands about car design and have him sit beside me to kind of join me in designing the car. We can also think about a means for the architect to interact with the public. This parametric system would become accessible, but the design would not become entirely public. You need to assist the process. I can imagine that for example my sister would ask me if I can sit by her or take a look at what she designed. (...) This distinction that we currently make: an architecture that employs parametric design and architecture that doesn't.

P.V.: No doubt that parametric design and generative design are changing the practice of architecture. How do you see the relation between parametric and generative design and spatial solutions, beyond the design of components and customization and digital fabrication, but for the development of novel spatial solutions? Is this changing with parametric design or is it difficult to deal with this kind of problem?

B.K.: Well, parametric design is well accepted in the design community. It is reaching the public domain. It is becoming accessible for people. There are manufacturers of prefabricated homes making identical houses. They have like five different types that people can choose from. We could have the home designs done online and the public could engage in them. You could have some dimensional ranges in $\mathrm{x}$ and $\mathrm{y}$. One can create hundreds of thousands of different homes. They would be the same type but just slightly different. These houses are based on a standard typology. I'm not sure that in Brazil you have that commercial provision of homes, but I believe this will become stronger. That I think is the next frontier of parametric design; the public engagement of these technologies.

\section{P.V.: Do you see open source design as a new frontier?}

B.K.: Yes! You could take a design of a major house, and you run the world and you can open that design and change it by parametrics, and have public engagement on that design.

G.C.: Thanks a lot Branko! We learned a lot from you today!

B.K.: It was my pleasure!

\section{Acknowledgments}

To Pedro Veloso, for his competent revision of the transcription.

\section{Notes}

(1) See www.generativeart.com/on/cic/abst2000/abst99.htm and cumincades.scix.net/data/works/att/67f4.content.pdf.

(2) Prof. Bill Mitchell used the book The Art of Computer Graphics Programming by Mitchell, Ligget and Kvan, in this class - see http://lapac.fec.unicamp.br/index.php/re/programming/projects/taocgp/ for the translation of the programs in the book into Processing.

(3) The Logic of Architecture was translated to Portuguese by Gabriela Celani and is available by Unicamp's press http://www.editora.unicamp.br.

About the participants (in the order of appearance)

BRANKO KOLAREVIC is a Professor at Calgary University, and the author of many articles and books about digital fabrication, performative architecture and digital design. He is an architect and holds a PhD from Harvard GSD, where he was advised by Professor Bill Mitchell.

GABRIELA CELANI is the founder of LAPAC, the Laboratory of Automation and Prototyping for Architecture and Construction, at the University of Campinas (http://lapac.fec.unicamp.br). She is an architect and holds a PhD from MIT, where she was advised by Professors Bill Mitchell and Terry Knight.

JARRYER DE MARTINO is an architect, a Master of Architecture and a PhD candidate at Unicamp. He works with evolutionary algorithms.

WILSON BARBOSA NETO is an architect who has just finished his master degree at Unicamp. He worked with applications of CNC plasma cutting in architecture and design. 
DANIEL LENZ has a background in both mechatronics and architecture, and is currently developing his master degree at Unicamp. He is interested in responsive architecture.

PEDRO GIACHINI is a final year undergraduate student in Civil Engineering at Unicamp. He is also an intern at Arup-SP.

FABIO AZEVEDO is a computer scientist and an MsC candidate at Unicamp. He is interested in the use of algorithmic animation for teaching programming for architecture students.

MAYCON SEDREZ is an architect, a Master of Architecture, and a PhD candidate at Unicamp. He studies complexity and the use of fractal geometry in the creation of a new type of ornament, with the use of digital fabrication tools.

ANDRÉ ARAÚJO is an architect, a Master of Architecture, and a PhD candidate at Unicamp. He works with parametric modeling and algorithmic design of truss structures.

PEDRO VELOSO is an architect, a Master of Architecture, and a PhD candidate at the University of São Paulo in São Carlos. He is interested in design computing philosophy.

VINICIUS MIZOBUTI is an undergrad architecture student at Unicamp. He develops an undergraduate research project about origami geometry, using Grasshopper as a modeling tool. 